\title{
The Impact of the Concussion Crisis on Safeguarding in Sport
}

\author{
Dominic Malcolm* \\ School of Sport, Exercise and Health Sciences, Loughborough University, Loughborough, United Kingdom \\ Keywords: brain injury, chronic traumatic encephalopathy, concussion, safeguarding, regulation, medicine
}

\section{INTRODUCTION}

For $\sim 30$ years, sociologists have explored the distinct ways in which athletes experience injury (Young, 2019). This work has explained the apparent high incidence of injury in relation to subcultural factors such as the dominance of masculinity (McGannon et al., 2013) and the specific organizational dynamics of sport (Nixon, 1992). Walk (1997, p. 24) perceptively noted that the implication of these analyses was that "medicine is practiced differently, more competently, and/or more ethically in non-sports contexts," a hypothesis that has largely been borne out by subsequent empirical analyses (Malcolm, 2017). Indicatively, a study of English professional football concluded that "many clubs fail to meet the requirements of health and safety legislation" (Murphy and Waddington, 2011, p. 239). A high incidence of injury allied to limited or substandard healthcare runs contrary to the guiding principles of safeguarding in sport.

In the last decade, rising public health concerns about brain injuries in sport-both concussion and chronic traumatic encephalopathy (CTE) - have reinvigorated this field. Specifically, as coroners decreed that the neurodegenerative illnesses of former athletes were a form "industrial disease," questions were asked about the sport's subcultural practices and a range of harm reduction measures were initiated. The previous routine dismissal of concussions as short-lived and relatively trivial events has been replaced by claims that there is now a concussion epidemic or crisis (Malcolm, 2020). Public support for sports injury safeguarding measures is perhaps stronger now than at any time in recent history.

This opinion piece explores the impact of this concussion crisis on injury prevention and safeguarding in sport. It outlines the significant changes that have been made in recent years and the problematic or potentially limiting aspects of these changes. The discussion identifies three farreaching changes required to promote further safeguarding and de-institutionalize physical harm to sport participants.

\section{HOW AWARENESS OF CONCUSSION HAS MADE SPORT SAFER}

This article was submitted to The History, Culture and Sociology of

a section of the journal Frontiers in Sports and Active Living

Received: 30 July 2020 Accepted: 03 February 2021 Published: 25 February 2021

Citation: Malcolm D (2021) The Impact of the Concussion Crisis on Safeguarding in

Concerns about brain injuries in sport stimulated political inquiries which have subsequently forced sports organizations to reconsider their duties to protect participants at all playing levels. Most notably, in a 2009 Congressional hearing the National Football League (NFL) were accused of neglect in both protecting current players from injury and managing the cases of retired players exhibiting cognitive decline. The response of the NFL was to repeatedly cast doubt and uncertainty over the reliability of scientific evidence and the causal connection between playing the game and player harm (Goldberg, 2013). Congress viewed the NFL as having fallen "short of community and government expectations" and failing "to regulate its sport for and in the best interests of the players and the public" (Greenhow and East, 2015, p. 75, 76). In 2015, a class action lawsuit concluded when the NFL agreed to establish a $\$ 1$ bn player compensation fund. These events were clearly and vividly depicted in the influential film and book League of Denial (Fainaru-Wada and Fainaru, 2013), and the publicity surrounding the NFL's experiences alerted sports governing bodies 
around the world to their duties of care, candor (or openness), and diligence in actively searching for relevant information about the physical harms to players (Anderson, 2016).

In response to their duty of care, governing bodies of most (if not all) contact sports have integrated specific clauses about the management of concussion into their rules and regulations. Many sports have instigated rule changes which seek to limit the extent or type of contact between players/playing equipment (McGannon et al., 2013; Cassilo and Sanderson, 2018). Sports teams are now constrained in their management of concussion through requirements to undertake sideline evaluations, restrictions on the return to play of diagnosed players, and the use of concussion spotters or non-affiliated doctors to assess head injuries. They are further enabled through adaptations to substitution regulations for players with suspected concussions. Many sports have also instigated their own concussion awareness or education programmes. Player education programmes are mandatory in youth sport across the USA following the adoption of the Lystedt Law, while similar provisions are likely to be introduced across Canada following the adoption of Rowan's Law in Ontario.

In response to their duty of diligence, governing bodies for many contact sports have funded research programmes. Studies have focused on quantifying the incidence of injury (West et al., 2020), assessing harm mitigation developments (e.g., improved helmet design, the impact of new laws and training programmes), and (occasionally) charting the longer-term neurocognitive decline of retired athletes (Hume et al., 2017; Mackay et al., 2019). Such research is inherently controversial. While failure to fund scientific research can lead to allegations of neglect (e.g., in the case of the National Hockey League), commissioning research can be interpreted as undermining the essential neutrality of scientific investigation and thus unduly influencing the evidence base. Undertaking due diligence can also evoke criticisms about governing bodies' duty of candor (Carlisle, 2018). In 2015, World Rugby clashed with their academic investigator over the interpretation of research findings (https://www.nzherald.co.nz/ sport/news/article.cfm?c_id=4\&objectid=11658681) and in 2017 was forced to retract some of the claims made in publicity materials about the relative safety of the sport (Piggin and Pollock, 2017).

The consequence of these combined changes is that the protection of concussed athletes is greater than at any point in history. Overall, however, the concussion crisis has meant that governing bodies have a heightened awareness of the injuries participants routinely experience, more proactively investigate health risks, and have enacted harm reduction changes.

\section{THE LIMITS OF CHANGE}

Despite these developments, three features of the concussion crisis effectively restrict the degree of protection offered by these harm mitigation policies.

First, all existing concussion protocols are premised on the assumption that injuries should be managed as discrete rather than cumulative events. Specifically, while both the immediate withdrawal of players suspected of being concussed and graduated return to play (GRTP) protocols represent important safeguarding measures, there are no regulations which govern players who experience multiple concussions. The empirical evidence is contested but, at the very least, data indicating that symptoms may become more frequent and severe, and potentially also lead to longer-term neurocognitive decline, suggest the "first do no harm" medical ethical principle is inconsistently applied (McNamee et al., 2015).

Second, regulations consistently treat children more conservatively than adults, e.g., through longer "normal recovery" times and elongated GRTP protocols (McCrory et al., 2017). Again the empirical evidence is inconsistent and paternalistic concerns largely account for the restrictions placed on youth sport involvement. It is not clear why mandatory concussion education (e.g., under the Lystedt Law) should be implemented for children and not adults. Paternalistic protection of the child must not obscure the need to address the harms experienced by adults. A more logical response to studies which associate the development of neurocognitive conditions with exposure to sport (Mackay et al., 2019) is to restrict the maximum duration of participants' playing careers.

Third, policies have been introduced with seemingly naïve expectations of compliance. Qualitative research demonstrates the challenges healthcare professionals experience in pursuing medical best practice in sports contexts (Malcolm, 2018) and indicates that stricter regulation may be counterproductive (Malcolm, 2009). Cusimano et al. (2017) argued that concussion protocols were followed in just $37 \%$ of cases during the 2014 FIFA World Cup. Others have pointed to a lack of monitoring and effective sanction to properly enforce concussion regulations in both Australia (Partridge, 2014) and the USA (Mrazik et al., 2015).

\section{DISCUSSION: THE FUTURE OF CONCUSSION AND SAFEGUARDING}

The two sides of the concussion crisis debate remain polarized between those who insist that greater restrictions on individual liberty are justified by the need to protect participants (especially children) from harm, and those who believe the value of sports participation (especially physical and mental health benefits) outweigh the potential risks (Quarrie et al., 2017). Consequently, the regulation of concussion in sport remains a "wicked problem"; complex, difficult to define and continuously evolving (Greenhow and East, 2015). These tensions are likely to fuel continuous incremental safeguarding adaptations, but more radical reforms will require three main reconsiderations.

1. Reconfiguring the regulatory environment. The guiding ideologies of public health and sports medicine are, respectively, the prevention of harm/promotion of safety and enabling participation and performance (Safai, 2003). Consequently, these two groups view the standards of evidence and burdens of proof required for concussionrelated changes from different ends of a spectrum. For as long as sport governing bodies retain their current levels of 
autonomy over concussion regulation, the public health lobby will remain frustrated. However, the historic consensus that sports should operate a significant level of self-governance has been eroded in recent years, particularly in relation to financial management, doping, and child protection. This creates a precedent for further changes to athlete healthcare. Momentum may now be sufficient to initiate collaborative state-sport approaches-akin perhaps to the dual funding of the World Anti-Doping Agency-and hence bring these often opposing medical fields together in the regulation of sport.

2. Reinforcing the ethical norms of medical management. The context, clients and co-workers experienced in sport create distinct pressures on healthcare workers (Malcolm, 2017). Bucking societal trends, there is a clear case for greater medical autonomy in sport as a way of addressing the problems Walk (1997) initially identified. The use of "neutral" medical staff to aid sideline concussion assessments is a step in this direction, but these measures are limited to diagnosis rather than ongoing management and rehabilitation from injury. Securer contractual arrangements, more rigorous appointment procedures, and greater oversight from the medical profession will not only help raise the standards of healthcare for concussion, but for all types of injury in sport (Waddington et al., 2019).

\section{REFERENCES}

Anderson, J. (2016). Concussion, Sport and the Law. Available online at: http:// www.sportsintegrityinitiative.com/concussion-sport-and-the-law/

Carlisle, W. (2018). The AFL's Concussion Problem: Is the League Running Interference on the Damage Concussion Can Cause? Available online at: https:// www.themonthly.com.au/issue/2018/september/1535724000/wendy-carlisle/ afl-s-concussion-problem

Cassilo, D., and Sanderson, J. (2018). "I don't think it's worth the risk": media framing of the Chris Borland retirement in digital and print media. Commun. Sport 6, 86-110. doi: 10.1177/2167479516654513

Cusimano, M., Casey, J., Jing, R., Mishra, A., Solarski, M., Techar, K., et al. (2017). Assessment of head collision events during the 2014 FIFA World Cup tournament. J. Am. Med. Assoc. 317, 2548-2549. doi: 10.1001/jama.2017.6204

Fainaru-Wada, M., and Fainaru, S. (2013). League of Denial. New York, NY: Crown Business.

Frey, J. H. (1991). Social risk and the meaning of sport. Sociol. Sport J. 8, 136-145. doi: $10.1123 /$ ssj.8.2.136

Goldberg, D. (2013). Mild traumatic brain injury, the national football league, and the manufacture of doubt: an ethical, legal, and historical analysis. J Legal Med. 34, 157-191. doi: 10.1080/01947648.2013.800792

Greenhow, A., and East, J. (2015). Custodians of the game: ethical considerations for football governing bodies in regulating concussion management. Neuroethics 8, 65-82. doi: 10.1007/s12152-014-9216-1

Hughes, R., and Coakley, J. (1991). Positive deviance among athletes: the implications of overconformity to the sport ethic. Sociol. Sport J. 8, 307-325. doi: $10.1123 /$ ssj.8.4.307

Hume, P., Theadom, A., Lewis, F., Quarrie, K., Brown, S., Hill, R., et al. (2017). A comparison of cognitive function in former rugby union players compared with former non-contact-sport players and the impact of concussion history. Sports Med. 47, 1209-1220. doi: 10.1007/s40279-016-0608-8

Liston, K., McDowell, M., Malcolm, D., Scott, A., and Waddington, I. (2018). On being "Head Strong": the pain zone and concussion in non-elite rugby union. Int. Rev. Sociol. Sport 53, 668-684. doi: 10.1177/10126902166 79966
3. Invoking comprehensive cultural change. Sustained and enduring change requires a cultural shift. All stakeholdersowners, coaches, athletes, medical staff, the media, parents, educators-have a role to play in questioning sport cultural norms around the tolerance of pain and injury (Frey, 1991; Hughes and Coakley, 1991), acceptance of harm, and celebration of risk-taking (Liston et al., 2018; Matthews, 2020). While the concussion crisis has been effective in raising social awareness of these issues, a major unintended consequence of extended regulation has been to position concussion as a unique form of injury. Consequently, this precautionary stance may be unnecessarily restricted to concussion injuries. Further safeguarding in sport requires these underlying precautionary principles to be transferable to other injury risks. Paradoxically, making concussion unexceptional is necessary for the relatively high injury rates to be more effectively challenged.

\section{AUTHOR CONTRIBUTIONS}

The author confirms being the sole contributor of this work and has approved it for publication.

Mackay, D., Russell, E., Stewart, K., MacLean, J., Pell, J., and Stewart, W. (2019). Neurodegenerative disease mortality among former professional soccer players. N. Engl. J. Med. 381, 1801-8. doi: 10.1056/NEJMoa1908483

Malcolm, D. (2009). Medical uncertainty and clinician-athlete relations: the management of concussion injuries in Rugby Union. Sociol. Sport J. 26, 191-210. doi: 10.1123/ssj.26.2.191

Malcolm, D. (2017). Sport, Medicine and Health: the Medicalization of Sport? London: Routledge. doi: 10.4324/9781315739311

Malcolm, D. (2018). Concussion in sport: public, professional and critical sociologies. Sociol. Sport J. 35, 141-148. doi: 10.1123/ssj.2017-0113

Malcolm, D. (2020). The Concussion Crisis in Sport. London: Routledge. doi: 10.4324/9780429292408

Matthews, C. R. (2020). “The fog soon clears”: bodily negotiations, embodied understandings, competent body action and "brain injuries" in boxing. Int. Rev. Sociol. Sport. doi: 10.1177/1012690220907026

McCrory, P., Meeuwisse, W., Dvorak, J., Aubry, M., Bailes, J., Broglio, S., et al. (2017). Consensus statement on concussion in sport - the $5^{\text {th }}$ international conference on concussion in sport held in Berlin, October 2016. Br. J. Sports Med. 51, 838-847. doi: 10.1136/bjsports-2017-097699

McGannon, K., Cunningham, S., and Schinke, R. (2013). Understanding concussion in socio-cultural context: a media analysis of a National Hockey League star's concussion. Psychol. Sport Exerc. 14, 891-899. doi: 10.1016/j.psychsport.2013.08.003

McNamee, M., Partridge, B., and Anderson, L. (2015). Concussion in sport: conceptual and ethical issues. Kinesiol. Rev. 4, 190-202. doi: 10.1123/kr.2015-0011

Mrazik, M., Dennison, C., Brooks, B., Yeates, K. O., Babul, S., and Naidu, D. (2015). A qualitative review of sports concussion education: prime time for evidence-based knowledge translation. Br. J. Sports Med. 49, 1548-1553. doi: 10.1136/bjsports-2015-094848

Murphy, P., and Waddington, I. (2011). Are elite athletes exploited? Sport Soc. 10, 239-255. doi: 10.1080/17430430601147096

Nixon, H. L. (1992). A social network analysis of influences on athletes to play with pain and injuries. J. Sport Soc. Issues 16, 127-135. doi: $10.1177 / 019372359201600208$ 
Partridge, B. (2014). Dazed and confused: sports medicine, conflicts of interest, and concussion management. Bioethic. Inq. 11, 65-74. doi: $10.1007 /$ s11673-013-9491-2

Piggin, J., and Pollock, A. (2017). World rugby's erroneous and misleading representation of Australian sports' injury statistics. Br. J. Sports Med. 51:1108. doi: 10.1136/bjsports-2016-096406

Quarrie, K., Brookes, J., Burger, N., Hume, P., and Jackson, S. (2017). Facts and values: on the acceptability of risks in children's sport using the example of rugby - a narrative review. Br. J. Sports Med. 51, 1134-1139. doi: 10.1136/bjsports-2017-098013

Safai, P. (2003). Healing the body in the "culture of risk:" examining the negotiations of treatment between sport medicine clinicians and injured athletes in Canadian intercollegiate sport. Sociol. Sport J. 20, 127-146. doi: $10.1123 /$ ssj.20.2.127

Waddington, I., Malcolm, D., and Scott-Bell, A. (2019). The social management of medical ethics in sport: confidentiality in English professional football. Int. Rev. Sociol. Sport 54, 649-665. doi: 10.1177/1012690217733678

Walk, S. (1997). Peers in pain: the experiences of student athletic trainers. Sociol. Sport J. 14, 22-56. doi: 10.1123/ssj.14.1.22
West, S., Starling, L., Kemp, S., Williams, S., Cross, M., Taylor, A., et al (2020). Trends in match injury risk in professional male rugby union: a 16season review of 10851 match injuries in the English Premiership (20022019): the Professional Rugby Injury Surveillance Project. Br. J. Sports Med. doi: 10.1136/bjsports-2020-102529

Young, K. (2019). The Suffering Body in Sport: Shifting Thresholds of Pain, Risk and Injury. Bingley: Emerald.

Conflict of Interest: The author declares that the research was conducted in the absence of any commercial or financial relationships that could be construed as a potential conflict of interest.

Copyright (C) 2021 Malcolm. This is an open-access article distributed under the terms of the Creative Commons Attribution License (CC BY). The use, distribution or reproduction in other forums is permitted, provided the original author(s) and the copyright owner(s) are credited and that the original publication in this journal is cited, in accordance with accepted academic practice. No use, distribution or reproduction is permitted which does not comply with these terms. 